\title{
Awareness of diabetic nephropathy in patients with type 2 diabetes mellitus: the Indian scenario
}

\author{
Chirag Bansal, Reshma Kaushik*, Rajeev Mohan Kaushik \\ Department of Medicine, Himalayan Institute of Medical Sciences, Swami Rama Himalayan University, Dehradun, Uttarakhand, India
}

\section{A R T I C L E I N F O}

Article Type:

Original

\section{Article History:}

Received: 7 January 2018

Accepted: 4 May 2018

ePublished: 20 May 2018

\section{Keywords:}

Awareness

Type 2 diabetes mellitus

Diabetic nephropathy

\begin{abstract}
A B S T R A C T
Introduction: Diabetic nephropathy is an important complication of diabetes mellitus leading to significant morbidity and mortality.

Objectives: To study the awareness of diabetic nephropathy in patients with type 2 diabetes mellitus (T2DM) and the factors influencing patient awareness of diabetic nephropathy.

Patients and Methods: Four hundred subjects, aged above 18 years with T2DM as per American Diabetes Association (ADA) criteria, were selected. Patient awareness regarding diabetic nephropathy was assessed as per a prefixed questionnaire.

Results: Awareness of basic information concerning diabetes was present in more than $60 \%$ of patients. No significant differences were seen between awareness scores of male and female $(P=0.385)$, rural and urban $(P=0.120)$ and literate and illiterate $(P=0.567)$ diabetic patients. Awareness scores were higher in diabetic patients exceeding 50 years of age $(P=0.004)$ and patients having diabetes for more than10 years $(P<0.0001)$, controlled diabetes $(P=0.026)$ and diabetic nephropathy $(P<0.0001)$. Awareness of diabetic nephropathy was independently associated with duration of diabetes $(P=0.010)$ and diabetic nephropathy $(P=0.011)$ but not with age $(P=0.754)$ and control of diabetes $(P=0.229)$. Conclusion: A substantial proportion of diabetic patients are still unaware of the basic facts about diabetes and diabetic nephropathy. Awareness of diabetic nephropathy depended upon duration of diabetes and presence of diabetic nephropathy and requires promotion during early stages of diabetes to improve control of diabetes and prevent diabetic nephropathy.
\end{abstract}

Implication for health policy/practice/research/medical education:

In a study on 400 diabetic patients, we found awareness of diabetic nephropathy was marginally higher in patients staying in urban areas and in literate patients. Better awareness of diabetic nephropathy was seen in older patients and patients with diabetes for a long duration, controlled diabetes and diabetic nephropathy but only duration of diabetes and diabetic nephropathy had an independent association with awareness of diabetic nephropathy.

Please cite this paper as: Bansal C, Kaushik R, Kaushik RM. Awareness of diabetic nephropathy in patients with type 2 diabetes mellitus: the Indian scenario. J Nephropharmacol. 2018;7(2):90-97.

\section{Introduction}

The prevalence of diabetes is rapidly increasing all over the world at an alarming rate (1) with 347 million diabetics present worldwide (2). As per WHO estimates, diabetes will become the seventh leading cause of death in 2030 (3). Based on the compilation of studies from different parts of the world, the estimated number of people with diabetes worldwide is expected to rise to 642 million by 2040 (4). India is the world leader with the largest proportion of diabetic patients and is distinguished as the "diabetes capital of the world". According to the international diabetes federation, the number of patients with diabetes in India is likely to rise to 69.9 million by 2025 unless urgent preventive measures are adopted (5).
Diabetes mellitus (types 1 and 2), is the foremost cause of incident and prevalent chronic kidney disease (CKD) and accounts for approximately $30 \%$ to $40 \%$ CKD and up to $45 \%$ of end-stage renal disease (6). In the past 2 decades, there has been a steady rise in the incidence of end-stage renal disease among patients with diabetes, mostly those with type 2 diabetes as per the reports of the US renal data system. Type 2 diabetes mellitus (T2DM) accounts for about $40 \%$ of all the prevailing end-stage renal disease cases and nearly half of all new cases in the United States (7).

Diabetic nephropathy is a principal cause of morbidity and has an association with increased cardiovascular mortality in T2DM. There is definite evidence that risks 
of nephropathy and of other diabetic complications are lowered by a strict control of hyperglycemia (8).

Diabetic awareness lacks among health professionals across Asia. Many of them do not record the height/ weight and body mass index (BMI) of their patients (9). The ability to manage diabetes can be impeded by the patient's lack of knowledge about diabetes care and is important as the patient's self-management ability is related to a better control of diabetes. Most of the patients with CKD, particularly those in the early stages, may not be aware of their disease (10). Several studies have shown that low awareness of the disease is common among CKD patients in the American society. Some reports of CKD identification and/or awareness, especially from outside the United States show that worldwide, both health providers and populace do not pay enough attention to increase CKD identification (11).

\section{Objectives}

We studied the awareness of diabetic nephropathy in patients with T2DM and the factors affecting patient awareness of diabetic nephropathy.

\section{Patients and Methods}

The study was conducted in the Department of Medicine, Himalayan Institute of Medical Sciences (HIMS), Swami Ram Nagar, Dehradun, India from March 1, 2014 to February 28, 2015. Patients with T2DM attending medical out-patient department or admitted in the medical wards were selected for the study after obtaining written informed consent.

\section{Study design}

Type of the study: cross-sectional descriptive study with a sample size of 400 individuals. It was calculated on the basis of formula $n=z^{2} p q / d^{2}$, where $n$ is desired sample size, $p$ is expected prevalence of awareness of diabetic nephropathy in diabetic population, $\mathrm{q}$ is $1-\mathrm{p} . \mathrm{z}$ is 1.96 (standard error) and $d$ is the level of statistical significance (0.05). Since percentage of patients aware of diabetic nephropathy among diabetic patients is unknown, a $P$ value of $50 \%$ was used to maximize uncertainty. Sample size obtained was 384 which was increased to 400 to accommodate the drop outs.

\section{Selection of subjects}

Inclusion criteria were age above 18 years and patients with T2DM. Exclusion criteria were patients with type 1 diabetes mellitus and newly diagnosed patients with T2DM.

\section{Study protocol}

All eligible patients attending the medical OPD or admitted in the medical wards of the Himalayan Institute Hospital, Dehradun, India with T2DM were included in the study. Diagnosis of diabetes mellitus was made as per American Diabetes Association (ADA) criteria (12). ADA criteria for the diagnosis of diabetes mellitus included one of the following; fasting plasma glucose $\geq 7.0 \mathrm{mmol} / \mathrm{L} \mathrm{(} \geq 126 \mathrm{mg} /$ $\mathrm{dL}$ ), symptoms of diabetes plus a random plasma glucose concentration $\geq 11.1 \mathrm{mmol} / \mathrm{L}(\geq 200 \mathrm{mg} / \mathrm{dL})$, 2 -h plasma glucose $\geq 11.1 \mathrm{mmol} / \mathrm{L}(\geq 200 \mathrm{mg} / \mathrm{dL})$ during a $75-\mathrm{g}$ oral glucose tolerance test, $\mathrm{HbA} 1 \mathrm{c} \geq 6.5 \%$.

Patients were subjected to detailed history plus clinical examination and following investigations were done: Complete blood count (CBC), fasting blood sugar, postprandial blood sugar, glycosylated hemoglobin, blood urea nitrogen, serum creatinine, serum lipid profile, urine analysis, spot urine for protein-creatinine ratio, electrocardiography (ECG), X-ray chest (posteroanterior view), ultrasonography of abdomen and fundoscopy. Patient awareness and attitude regarding diabetic nephropathy were assessed as per questions specified in the questionnaire designed for checking patient awareness regarding diabetic nephropathy. A score of 1 was given to every correct answer and 0 for every incorrect response with a maximum score up to 25 in the questionnaire.

\section{Ethical issues}

Ethical clearance for the study was taken from the institutional ethical committee. All investigations/ procedures carried out in this study involving human participants were in accordance with the 1975 Declaration of Helsinki and its later amendments.

\section{Statistical analysis}

The data collected were analyzed with SPSS software version 19.0. The data were expressed as mean \pm standard deviation (SD) for continuous variables and as frequency or percentage for categorical variables. Student's $t$ test was used for comparison of continuous data and chi-square test for testing the significance of difference between proportions. Logistic regression analysis was used for testing the independent association of various variables with awareness of diabetic nephropathy. Additionally, $P$ values less than 0.05 were considered statistically significant.

\section{Results}

Baseline characteristics of the patients with T2DM are shown in Table 1. Mean age of the patients was $54.80 \pm$ 12.87 years. The majority $(88.0 \%)$ of the patients were below the age of 70 years. Male predominance was seen with male: female ratio of $2.8: 1$. The majority $(65.5 \%)$ of the diabetic patients were from rural area. BMI range was from 15.05 to 34.7. About half of the patients had diabetes for 1 to 5 years (Table 1 ).

Polyuria, polydipsia and blurring of vision were the most common symptoms while absent ankle reflex and changes of diabetic retinopathy were the most common examination findings. Diabetic neuropathy and retinopathy were the most common diabetic complications followed by diabetic nephropathy (Table 2). The fasting blood sugar range was from $102 \mathrm{mg} / \mathrm{dL}$ to $403 \mathrm{mg} / \mathrm{dL}$ and that of post-prandial 
Table 1. Baseline characteristics of patients with T2DM

\begin{tabular}{|c|c|}
\hline Characteristics & No. of patients (\%)/Mean \pm SD \\
\hline \multicolumn{2}{|l|}{ Age group } \\
\hline $31-40$ years & $81(20.25)$ \\
\hline $41-50$ years & $82(20.50)$ \\
\hline $51-60$ years & $97(24.25)$ \\
\hline $61-70$ years & $92(23)$ \\
\hline $71-80$ years & $39(9.75)$ \\
\hline$>80$ years & $9(2.25)$ \\
\hline \multicolumn{2}{|l|}{ Gender } \\
\hline Males & $295(73.75)$ \\
\hline Females & $105(26.25)$ \\
\hline \multicolumn{2}{|l|}{ Residence } \\
\hline Rural & $262(65.5)$ \\
\hline Urban & $138(34.5)$ \\
\hline \multicolumn{2}{|l|}{ Socioeconomic status } \\
\hline High & $54(13.5)$ \\
\hline Middle & $119(29.75)$ \\
\hline Low & $227(56.75)$ \\
\hline \multicolumn{2}{|l|}{ Dietary habits } \\
\hline Vegetarian & $288(72)$ \\
\hline Mixed diet eaters & $112(28)$ \\
\hline \multicolumn{2}{|l|}{ Literacy status } \\
\hline Literate & $178(44.5)$ \\
\hline Matriculate & $129(32.25)$ \\
\hline Graduate & $41(10.25)$ \\
\hline Post-graduate & $8(2)$ \\
\hline Illiterate & $222(55.5)$ \\
\hline Smoker & $167(41.75)$ \\
\hline Non-smoker & $233(58.25)$ \\
\hline Alcoholic & $97(24.25)$ \\
\hline Non-alcoholic & $303(75.75)$ \\
\hline Tobacco chewer & $40(10)$ \\
\hline Non-tobacco chewer & $360(90)$ \\
\hline Height (cm) & $165.07 \pm 7.73$ \\
\hline Weight (kg) & $65.03 \pm 11.82$ \\
\hline BMI $\left(\mathrm{kg} / \mathrm{m}^{2}\right)$ & $23.58 \pm 4.23$ \\
\hline \multicolumn{2}{|l|}{ Duration of diabetes } \\
\hline $1-5$ years & $202(50.5)$ \\
\hline $6-10$ years & $115(28.75)$ \\
\hline$>10$ years & $83(20.75)$ \\
\hline
\end{tabular}

T2DM, type 2 diabetes mellitus; BMI, body mass index.

blood sugar $103 \mathrm{mg} / \mathrm{dL}$ to $477 \mathrm{mg} / \mathrm{dL}$. Controlled diabetes was seen in 59 patients and uncontrolled diabetes in 341 patients. Dyslipidemia was seen in 196 patients with high total serum cholesterol, high triglycerides, high LDL-C and low HDL-C either alone or in combination. Around 306 patients were on oral hypoglycemic drugs whereas 71 were on insulin, 8 on ayurvedic medicines and other patients on dietary management.

Awareness regarding basic information concerning diabetes was present in more than $60 \%$ of the patients. Awareness regarding importance of diet was seen in more than half of the patients. Knowledge of antidiabetic medications was poor in diabetic patients. The majority of patients were keen to know more about diabetes but only approximately one-fourth of patients were aware of the importance of need for annual health check-ups.
Table 2. Clinical features, complications and laboratory parameters of patients with T2DM $(n=400)$

\begin{tabular}{|c|c|}
\hline Clinical features & No. of patients $(\%) /$ Mean \pm SD \\
\hline \multicolumn{2}{|l|}{ Symptoms } \\
\hline Polydipsia & $220(55.0)$ \\
\hline Polyuria & $282(70.5)$ \\
\hline Weight loss & $120(30.0)$ \\
\hline Blurred vision & $216(54.0)$ \\
\hline Tingling sensation & $131(32.75)$ \\
\hline Joint pain & $76(19.0)$ \\
\hline Fatigue & $62(15.5)$ \\
\hline Obesity & $25(6.25)$ \\
\hline Diarrhea & $23(5.75)$ \\
\hline Constipation & $57(14.75)$ \\
\hline Difficulty in walking & $83(20.75)$ \\
\hline \multicolumn{2}{|l|}{ Signs } \\
\hline Pallor & $77(19.25)$ \\
\hline Pedal edema & $48(12.0)$ \\
\hline Ankle reflex absent & $151(37.75)$ \\
\hline \multicolumn{2}{|l|}{ Complications } \\
\hline Diabetic nephropathy & $74(18.5)$ \\
\hline Diabetic retinopathy & $208(52.0)$ \\
\hline Diabetic neuropathy & $249(62.25)$ \\
\hline Coronary artery disease & $22(5.5)$ \\
\hline Peripheral vascular disease & $39(9.75)$ \\
\hline History of cerebrovascular accidents & $20(5.0)$ \\
\hline \multicolumn{2}{|l|}{ Parameter (unit) } \\
\hline Hemoglobin (g/dL) & $13.03 \pm 1.95$ \\
\hline WBC count (cells $/ \mu \mathrm{L})$ & $6822.98 \pm 1562.70$ \\
\hline Platelet count (cells/ $\mu \mathrm{L}$ ) & $258.69 \pm 59.31$ \\
\hline $\mathrm{FBS}(\mathrm{mg} / \mathrm{dL})$ & $158.71 \pm 28.71$ \\
\hline PPBS (mg/dL) & $201.29 \pm 42.68$ \\
\hline Serum creatinine (mg/dL) & $1.39 \pm 0.93$ \\
\hline Blood urea nitrogen $(\mathrm{mg} / \mathrm{dL})$ & $31.97 \pm 13.13$ \\
\hline Total serum cholesterol (mg/dL) & $162.12 \pm 43.33$ \\
\hline Serum HDL-C (mg/dL) & $39.68 \pm 9.89$ \\
\hline Serum LDL-C (mg/dL) & $97.95 \pm 36.61$ \\
\hline Serum triglyceride (mg/dL) & $134.87 \pm 62.14$ \\
\hline Glycosylated hemoglobin (\%) & $8.28 \pm 2.03$ \\
\hline eGFR $\left(\mathrm{mL} / \mathrm{min} / 1.73 \mathrm{~m}^{2}\right)$ & $78.8 \pm 43.7$ \\
\hline $\begin{array}{l}\text { Urinary protein creatinine ratio }(\mathrm{mg} / \\
\mathrm{mg})\end{array}$ & $1.06 \pm 1.03$ \\
\hline Urinary albumin & $75(18.75)$ \\
\hline
\end{tabular}

T2DM, type 2 diabetes mellitus; WBC, white blood cell; FBS, fasting blood sugar; PPBS, post-prandial blood sugar; HDL, high density lipoprotein; LDL, low density lipoprotein; eGFR, estimated glomerular filtration rate; Urinary albumin- the number (\%) of diabetic patients having presence of albumin in urine.

Awareness regarding diabetic nephropathy was seen in approximately one-third of patients though more than half of the patients were informed by the treating physician regarding possibility of diabetic nephropathy and fall-outs in diabetes (Table 3).

Accordingly, no significant differences were seen between awareness scores of diabetic patients as per gender (male versus female), place of residence (rural versus urban), literacy status (literate versus illiterate), obesity status (obese versus non-obese) $(P>0.05$ each). Awareness scores were significantly higher in diabetic patients above 
Table 3. Awareness of diabetes and diabetic nephropathy among patients with T2DM

\begin{tabular}{|c|c|c|c|}
\hline \multirow{3}{*}{ Question } & \multirow{2}{*}{\multicolumn{2}{|c|}{$\begin{array}{l}\text { No. of patients (\%) } \\
\text { Awareness }\end{array}$}} & \multirow{3}{*}{$P$ value } \\
\hline & & & \\
\hline & Present & Absent & \\
\hline What is diabetes? & $395(98.75)$ & $5(1.25)$ & $<0.001$ \\
\hline Regarding normal blood sugar levels & $381(95.25)$ & $19(4.75)$ & $<0.001$ \\
\hline What are FBS and PPBS? & $335(83.75)$ & $65(16.25)$ & $<0.001$ \\
\hline Symptoms of diabetes & $260(65.0)$ & $140(35.0)$ & $<0.001$ \\
\hline Importance of diabetic diet & $226(56.5)$ & $174(43.5)$ & 0.009 \\
\hline Diabetic complications & $171(42.75)$ & $229(57.25)$ & 0.003 \\
\hline Diabetes can affect kidneys & $151(37.75)$ & $249(62.25)$ & $<0.001$ \\
\hline Kidney function status & $130(32.5)$ & $270(67.5)$ & $<0.001$ \\
\hline Importance of control of T2DM in preventing DN & $164(41.0)$ & $236(59.0)$ & 0.003 \\
\hline Increased frequency of micturition in DN & $250(62.5)$ & $150(37.5)$ & $<0.001$ \\
\hline Waking up for micturition during night in DN & $175(43.75)$ & $225(56.25)$ & 0.012 \\
\hline Association of frequent episodes of UTI with uncontrolled T2DM & $313(78.25)$ & $87(21.75)$ & $<0.001$ \\
\hline Significance of bubbles in urine & $106(26.5)$ & $294(73.5)$ & $<0.001$ \\
\hline Proteinuria in DN & $53(13.25)$ & $347(86.75)$ & $<0.001$ \\
\hline Willingness to go for renal function tests when asked by physicians & $320(80.0)$ & $80(20.0)$ & $<0.001$ \\
\hline Importance of need for annual health checkup for complications of T2DM & $111(27.75)$ & $289(72.25)$ & $<0.001$ \\
\hline Importance of hypoglycemia occurring in DN on same dose of medications as before & $114(28.5)$ & $286(71.5)$ & $<0.001$ \\
\hline Knowledge of antidiabetic medications & $33(8.25)$ & $367(91.75)$ & $<0.001$ \\
\hline Role of Hypertension in DN & $43(10.75)$ & $357(89.25)$ & $<0.001$ \\
\hline Effect of smoking on DN & $140(35)$ & $260(65)$ & $<0.001$ \\
\hline Keenness to know more about DN & $382(95.5)$ & $18(4.5)$ & $<0.001$ \\
\hline Whether informed by medical professional regarding DN & $235(58.75)$ & $165(41.25)$ & 0.005 \\
\hline Possible requirement of dialysis in DN & $144(36)$ & $256(64)$ & $<0.001$ \\
\hline Possibility of renal transplant in DN & $67(16.75)$ & $333(83.25)$ & $<0.001$ \\
\hline Renal transplant better than HD in severe DN & $29(7.25)$ & $371(92.75)$ & $<0.001$ \\
\hline
\end{tabular}

T2DM, type 2 diabetes mellitus; FBS, fasting blood sugar; PPBS, post-prandial blood sugar; DN, diabetic nephropathy; HD, hemodialysis.

50 years of age $(P=0.004)$ and those having diabetes of more than 10 years' duration $(P<0.0001)$. The controlled diabetic patients had higher awareness scores than the uncontrolled ones $(P=0.026)$. Diabetic nephropathy was present in $74(18.5 \%)$ patients. Awareness score was significantly more in patients with diabetic nephropathy than in patients without diabetic nephropathy $(P<0.0001)$. The mean awareness scores were $13 \pm 6.54$ in patients with CKD stage one, $11.6 \pm 6.84$ in stage two, $15.29 \pm 3.55$ in stage three, $13.63 \pm 6.38$ in stage four and $15.25 \pm 3.97$ in end-stage renal disease. No significant differences were seen between awareness scores of diabetic patients with early and advanced stages of diabetic nephropathy $(P=0.968)$ (Table 4).

The variables of age of the diabetic patients, duration of disease, control of diabetes and diabetic nephropathy showing significant differences between awareness scores of diabetic patients in various subgroups on univariate analysis were entered into logistic regression model for determining the factors having an independent association with awareness of diabetic nephropathy among diabetic patients by multivariate analysis. Awareness of diabetic nephropathy was considered to be present in patients having awareness scores above the median value and absent in those with scores below the median value. Duration of diabetes $(P=0.010)$ and diabetic nephropathy $(P=0.011)$ were found to have an independent association with awareness of diabetic nephropathy while age $(P=0.754)$ and control of diabetes $(P=0.229)$ were not independently associated with awareness of diabetic nephropathy (Table 5).

\section{Discussion}

The pattern of age distribution among diabetic patients demonstrated that the maximum number of patients were present in the age group of 51-60 years i.e. 97 (24.25\%) patients and the least in $>80$ years' age group with 9 (2.25\%) patients. A similar study by Whaley-Connell et al (13) showed maximum patients $(38.3 \%)$ in the age group of 46-60 years. The mean age of patients in our study was $54.80 \pm 12.87$ years. This finding is in accordance with the study done by Chow et al (14) in which the mean age of the respondents was $48.9 \pm 15.0$ years. Most of our patients were less than 70 years of age which may be due to less survival rate of patients with diabetes in elderly patients due to complications caused by uncontrolled diabetes. The gender distribution revealed a male preponderance in all age groups. The male population constituted a $73.75 \%$ 
Table 4. Comparison of awareness scores as per various parameters in patients with T2DM

\begin{tabular}{|c|c|c|c|}
\hline Parameters & $\begin{array}{c}\text { No. of } \\
\text { patients (\%) }\end{array}$ & $\begin{array}{c}\text { Scores } \\
\text { (Mean } \pm \text { SD) }\end{array}$ & $P$ value \\
\hline \multicolumn{4}{|l|}{ Age groups } \\
\hline$<50$ years & $163(40.75)$ & $10.98 \pm 4.64$ & 0.004 \\
\hline$>50$ years & $237(59.25)$ & $12.07 \pm 4.96$ & \\
\hline \multicolumn{4}{|l|}{ Gender } \\
\hline Males & $295(73.75)$ & $11.76 \pm 5.05$ & 0.385 \\
\hline Females & $105(26.25)$ & $11.29 \pm 4.30$ & \\
\hline \multicolumn{4}{|l|}{ Residence } \\
\hline Urban & $138(34.5)$ & $12.4 \pm 4.885$ & 0.120 \\
\hline Rural & $262(65.5)$ & $11.45 \pm 4.852$ & \\
\hline \multicolumn{4}{|l|}{ Obesity } \\
\hline Absent & 375 (93.75) & $11.29 \pm 4.30$ & 0.905 \\
\hline Present & $25(6.25)$ & $11.75 \pm 5.76$ & \\
\hline \multicolumn{4}{|c|}{ Duration of diabetes } \\
\hline $1-10$ years & $317(79.25)$ & $11.15 \pm 4.67$ & $<0.0001$ \\
\hline$>10$ years & $83(20.75)$ & $14.41 \pm 5.01$ & \\
\hline \multicolumn{4}{|c|}{ Control of diabetes } \\
\hline Controlled & 59 (14.75) & $12.95 \pm 4.967$ & 0.026 \\
\hline Uncontrolled & $341(85.25)$ & $11.43 \pm 4.809$ & \\
\hline \multicolumn{4}{|l|}{ Literacy } \\
\hline Literate & $178(44.5)$ & $11.8 \pm 5.04$ & 0.567 \\
\hline Illiterate & $222(55.5)$ & $11.52 \pm 4.72$ & \\
\hline \multicolumn{4}{|c|}{ Diabetic nephropathy } \\
\hline Present & $74(18.5)$ & $14.17 \pm 5.37$ & $<0.0001$ \\
\hline Absent & $326(81.5)$ & $11.07 \pm 4.56$ & \\
\hline \multicolumn{4}{|l|}{ Stages of DN } \\
\hline I-III & $28(37.84)$ & $14.14 \pm 4.96$ & 0.968 \\
\hline IV $-\mathrm{V}$ & $46(62.16)$ & $14.19 \pm 5.66$ & \\
\hline
\end{tabular}

T2DM, type 2 diabetes mellitus; DN, diabetic nephropathy.

of total patients exhibiting a trend similar to another study which had $66 \%$ males among the patients (15) while Chin et al (16) showed male predominance to the tune of $55.5 \%$ in their series. Similar observations were made in Pakistan by Ulvi et al (9) who noted male predominance with $63.67 \%$ of the males among total patients in their series. This observation may be because of excessive stresses and strains faced by males in day to day life in our country as mostly they are the bread earners and most of the females particularly the married ones are the housewives and are not exposed to stresses involved in earning livelihood.

We observed that $138(34.5 \%)$ patients were residents of urban area and they had a better mean awareness score (12.4) as compared to the residents of rural areas (11.45), although this was not significant statistically. The observed difference may be due to better availability of education and health facilities in the urban areas. It also implies that more educational centers and hospitals are required in our rural areas for imparting better education and raising health awareness.

In our study we found that the smokers were seen in large proportion $(41.75 \%)$ despite the fact that they were suffering from diabetes, similar to results of another study where total smokers were $42 \%$ (15). Only 35\% of our patients identified correctly the effect/risk of smoking on the diabetic nephropathy similar to observations of another study, where only $21.8 \%$ of the patients had knowledge about the risk or effect of smoking on the kidneys (17). It suggests that most of the diabetic patients are unaware of the risk factors for the diabetic nephropathy and appropriate measures should be taken by physicians to educate their patients about the modifiable risk factors. We found that only $130(32.50 \%)$ patients knew about their kidney function status and similar trend was observed by White et al (18) in Australia that only 39.7\% of the respondents remembered the last time they had a renal function test. This shows the lack of knowledge and interest of patients about their own disease and its complications which needs to be improved.

We observed that there were not many patients (151 patients, $37.75 \%$ ) who responded correctly to the question regarding the effect of diabetes on kidneys. In other questions concerning the symptomatology and manifestations of diabetic nephropathy, generally less than $50 \%$ respondents came out with correct answers. In a study from Benin, $57.50 \%$ diabetic patients were aware that diabetes mellitus could be complicated by renal impairment while $75.63 \%$ diabetics did not know that it was possible to diagnose diabetic nephropathy at an early stage (19). However, a study done in Iran by Roomizadeh et al (17) found that only $10.6 \%$ of the total patients identified diabetes as one of the main risk factors for CKD while only $10.4 \%$ responded correctly to the questions concerning the symptomatology and manifestations of diabetic nephropathy. These observations suggest that many Indians are not adequately informed about the symptoms and manifestations of the diabetic nephropathy and we need to evaluate this more extensively and proper measures should be taken to improve the awareness of public regarding this issue. We observed that 235 (58.75\%) patients had been informed by the medical professionals about diabetic nephropathy and its symptoms but only 53 (13.25\%) patients knew that the presence of proteins in urine was a sign of kidney disease. Similar kind of trend was observed in a study in the United States by Plantinga et al (20) where $64 \%$ of medical professionals informed their patients about diabetic nephropathy and its symptoms/complications but only $7 \%$ of the total patients knew that proteins in urine were a sign of kidney disease. It is apparent that a sizeable number of physicians try to educate their patients about diabetic nephropathy though much needs to be done to achieve the desired impact on patients.

We noted that formally educated patients had better awareness with maximum awareness among the postgraduates with score of 16.5 followed by graduates with a score of 12.49 and illiterates with a score of 11.52, although the differences between awareness scores of literate and illiterate diabetic patients were not found to be statistically significant $(P=0.567)$. Similar results were also found by White et al (18) who found that those with 
tertiary or secondary education had a better awareness of diabetic nephropathy than those who had not completed their secondary education $(P<0.001)$. Similar kind of pattern was observed in a study conducted by Ulvi et al (9) which showed that people who had formal education had a higher level of awareness (46.2\%) compared to people with no formal education (37\%), although this difference was not statistically significant $(P=0.46)$. Our observations suggest that with increasing level of education, the patient's awareness about the diabetes mellitus and its complications increased although the results were statistically not significant. Still there was a lot of difference in the mean scores of post-graduates and illiterates. Moreover, currently the educational status of the general public is not very good in our country and requires much to be done to improve the situation. It can help in early identification of diabetes by the patients and starting treatment at an early stage which can lead to better management of diabetes and prevent its complications. As per duration of diabetes mellitus, a significantly higher awareness score observed in patients with diabetes for more than 10 years could be due to patient education over years and also because of increase in patient's health concern once the kidneys started failing.

We observed higher awareness scores among controlled diabetics as compared to those among uncontrolled diabetics. It implies that those who had better control of diabetes had better awareness about diabetic nephropathy because they were more aware of their disease and paid more attention to their health status.

We found that the patients with diabetic nephropathy i.e. $74(18.5 \%)$ patients had better awareness as compared to the patients without diabetic nephropathy. This trend may be because of better information obtained about the disease during frequent visits to physicians for various complications.

We noted that with increasing stage of CKD, the awareness also showed an increasing trend i.e. the mean scores were $13 \pm 6.54$ in CKD stage one; $11.6 \pm 6.84$ in stage two, $15.29 \pm 3.55$ in stage three, $13.63 \pm 6.38$ in stage four and $15.25 \pm 3.97$ in end-stage renal disease. A similar trend of awareness was also observed in the study conducted by Chin et al (16) which showed that with increasing CKD stage the awareness was increasing, for example $1.6 \%$ for stage $1 \mathrm{CKD}, 1.5 \%$ for stage $2 \mathrm{CKD}, 3.8 \%$ for stage $3 \mathrm{CKD}$, $22.2 \%$ for stage $4 \mathrm{CKD}$ and $44.4 \%$ for end-stage kidney disease. Another study done by Hsu et al (11) showed that CKD awareness rates in Taiwan were low in the early stages of CKD i.e. $8.0 \%$ for people with stage 3, 25.0\% for people with stage 4 , and $71.4 \%$ for people with stage 5. However, awareness rates may not be accurate in the advanced CKD (stages 4 and 5) population in this study because of its small sample size. An increasing trend of awareness with increasing stages of diabetic nephropathy may be because of patients' observation of the frequent occurrence of the same symptoms in day to day life and frequent visits to physicians and nephrologists for the disease. However, the observation that patients with CKD with stages one and two have very less knowledge as compared to the patients with more advanced stages of the disease leaves a room for hard work for improving their awareness status regarding diabetic nephropathy so that the progression of diabetic nephropathy can be prevented by taking appropriate measures. Our observation of awareness of diabetic nephropathy having independent association with duration of diabetes $(P=0.010)$ and diabetic nephropathy $(P=0.011)$ appears to be due to patient education about the disease expected to increase as a result of repeated medical consultations over years and increased health consciousness of the patients once the kidneys are affected by diabetes. It implies that there is general lack of awareness regarding diabetes and its complications in the initial phase of the disease.

The rate of end-stage kidney disease has been stabilized in some countries, (21-25) probably due to improvement in the awareness of primary care physicians regarding the prognostic importance of CKD, improved control of blood pressure and glycemia and the execution of protocols and clinical practice recommendations about the detection, prevention and treatment of CKD in the management of the diabetic patient. Detection of DM and diabeticCKD at an early stage is crucial for reducing morbidity, mortality and the socio-economic impact of diabetes in the population (26). Hence, appropriate steps should be taken to promote such awareness at community level and among diabetic patients at an early stage of the disease so as to ensure a better control of diabetes and prevent diabetic complications.

\section{Conclusion}

A sizeable number of diabetic patients are still unaware regarding some of the basic facts about diabetes and diabetic nephropathy. Awareness was lacking regarding symptomatology, complications and treatment of diabetes/ diabetic nephropathy.

Awareness of diabetic nephropathy was marginally higher in patients staying in urban areas and in literate patients. Better awareness of diabetic nephropathy was seen in older patients and patients with diabetes for long duration, controlled diabetes and diabetic nephropathy but only duration of diabetes and diabetic nephropathy had an independent association with awareness of diabetic nephropathy. As such, putting an emphasis on promotion of awareness and knowledge of general public as well as diabetic patients regarding diabetes and its complications is warranted at all levels to ensure a better control of diabetes and prevent or delay diabetic nephropathy.

\section{Acknowledgments}

We are thankful to Shubham Pandey for his help in the statistical work. We appreciate the help of Madhurima Kaushik in checking the manuscript. 


\section{Authors' contribution}

RK and RMK conceived and designed the study. CB collected the patient data and prepared the initial manuscript. RK and RMK contributed to critical revision of the manuscript for important intellectual content. All authors analyzed and interpreted the data and approved the submitted manuscript.

\section{Conflicts of interest}

None

\section{Ethical considerations}

Ethical issues (including plagiarism, data fabrication, double publication) have been completely observed by the authors.

\section{Funding/Support}

The study was supported by the Himalayan Institute Hospital Trust, Dehradun, India.

\section{References}

1. Huizinga MM, Rothman RL. Addressing the diabetes pandemic: A comprehensive approach. Indian J Med Res. 2006; 124:481-4.

2. Danaei G, Finucane MM, Lu Y, Singh GM, Cowan MJ, Paciorek CJ, et al. Global Burden of Metabolic Risk Factors of Chronic Diseases Collaborating Group (Blood Glucose). National, regional, and global trends in fasting plasma glucose and diabetes prevalence since 1980: systematic analysis of health examination surveys and epidemiological studies with 370 country-years and 2.7 million participants. Lancet. 2011;378:31-40. doi: 10.1016/ S0140-6736(11)60679-X.

3. Diabetes. Global status report on non-communicable diseases 2010. Geneva: World Health Organization; 2011. http://www.who.int/nmh/publications/ncd_report2010/ en. Accessed April 14, 2018.

4. Diabetes. A global emergency. International Diabetes federation Diabetes Atlas. 7th edition, 2015. http://www. diabetesatlas.org. Accessed April 14, 2018.

5. Mohan V, Sandeep S, Deepa R, Shah B, Varghese C. Epidemiology of type 2 diabetes: Indian scenario. Indian J Med Res. 2007; 125:217-30.

6. KDOQI. KDOQI Clinical Practice Guidelines and Clinical Practice Recommendations for Diabetes and Chronic Kidney Disease. Am J Kidney Dis. 2007;49:S12-154. doi: 10.1053/j.ajkd.2006.12.005.

7. U.S. Renal Data System, USRDS 2006 Annual Data Report: Atlas of End-Stage Renal Disease in the United States, National Institutes of Health, National Institute of Diabetes and Digestive and Kidney Diseases, Bethesda, MD; 2006. https://www.usrds.org/atlas06.aspx. Accessed April 14, 2018.

8. Ravid M, Brosh D, Ravid-Safran D, Levy Z, Rachmani R. Main risk factors for nephropathy in type 2 diabetes mellitus are plasma cholesterol levels, mean blood pressure, and hyperglycemia. Arch Intern Med. 1988;158:998-1004. doi:10.1001/archinte.158.9.998.

9. Ulvi OS, Chaudhary RY, Ali T, Alvi RA, Khan MF, Khan $\mathrm{M}$, et al. Investigating the awareness level about diabetes mellitus and associated factors in Tarlai (rural Islamabad). J Pak Med Assoc. 2009; 59:798-801.

10. Plantinga LC, Boulware LE, Coresh J, Stevens LA, Miller ER 3rd, Saran R, et al. Patient awareness of chronic kidney disease: trends and predictors. Arch Intern Med. 2008;168:2268-75. doi: 10.1001/archinte.168.20.2268.

11. Hsu CC, Hwang SJ, Wen CP, Chang HY, Chen T, Shiu RS, et al. High prevalence and low awareness of CKD in Taiwan: A study on the relationship between serum creatinine and awareness from a nationally representative survey. Am J Kidney Dis. 2006;48:727-38. doi: 10.1053/j. ajkd.2006.07.018.

12. American Diabetes Association. Standards of Medical care in diabetes-2014. Diabetes Care. 2014; 37:S14-80. doi: $10.2337 / \mathrm{dc} 14-\mathrm{S} 014$.

13. Whaley-Connell A, Sowers JR, McCullough PA, Roberts T, McFarlane SI, Chen SC, et al. Diabetes mellitus and CKD awareness: The kidney early evaluation program (KEEP) and National health and nutrition examination survey (NHANES). Am J Kidney Dis. 2009;53:S11-21. doi: 10.1053/j.ajkd.2009.01.004.

14. Chow WL, Joshi VD, Tin AS, van der Erf S, Lim JF, Swah TS, et al. Limited knowledge of chronic kidney disease among primary care patients - a cross-sectional survey. BMC Nephrol. 2012;13:54. doi: 10.1186/1471-2369-13-54.

15. Whaley-Connell A, Shlipak MG, Inker LA, Kurella Tamura M, Bomback AS, Saab G, et al. Awareness of kidney disease and relationship to end-stage renal disease and mortality. Am J Med. 2012;125:661-9. doi: 10.1016/j. amjmed.2011.11.026.

16. Chin HJ, Ahn JM, Na KY, Chae DW, Lee TW, Heo NJ, et al. The effect of the World Kidney Day campaign on the awareness of chronic kidney disease and the status of risk factors for cardiovascular disease and renal progression. Nephrol Dial Transplant. 2010;25:413-9. doi: 10.1093/ndt/ gfp512.

17. Roomizadeh P, Taheri D, Abedini A, Mortazavi M, Larry M, Mehdikhani B, et al. Limited knowledge of chronic kidney disease and its main risk factors among Iranian community: an appeal for promoting national public health education programs. Int J Health Policy Manag. 2014;2:161-6. doi: 10.15171/ijhpm.2014.37.

18. White SL, Polkinghorne KR, Cass A, Shaw J, Atkins RC, Chadban SJ. Limited knowledge of kidney disease in a survey of AusDiab study participants. Med J Aust. 2008; 188:204-8.

19. Vigan J, Adja É, Zannou J, Agboton BL, Kérékou CA, Amoussou-Guenou D, et al. Means of communication for an early detection of diabetic nephropathy among the diabetics followed in the academic hospital of Cotonou. Nephrol Ther. 2014;10:165-9. doi: 10.1016/j.nephro.2013.12.005.

20. Plantinga LC, Delphine ST, Powe NR. Awareness of chronic kidney disease among patients and providers. Adv Chronic Kidney Dis. 2010;17:225-36. doi: 10.1053/j. ackd.2010.03.002.

21. Burrows NR, Li Y, Geiss LS. Incidence of treatment for endstage renal disease among individuals with diabetes in the U.S. continues to decline. Diabetes Care. 2010;33:73-7. doi: 10.2337/dc09-0343.

22. Comas J, Arcos E, Castell C, Cases A, Martínez-Castelao A, Doñate T, et al. Evolution of the incidence of chronic kidney disease stage 5 requiring renal replacement therapy in the 
diabetic population of Catalonia. Nephrol Dial Transplant. 2013;28:1191-8. doi: 10.1093/ndt/gfs507.

23. Dialysis and Transplantation annual report of the Spanish Society of Nephrology (S.E.N.)-ONT. Presented at: 44th Congress of the S.E.N.; Barcelona, Spain; 2014.

24. Grace BS, Clayton P, McDonalds SP. Increases in renal replacement therapy in Australia and New Zealand: Understanding trends in diabetic nephropathy. Nephrology (Carlton). 2012;17:76-84. doi: 10.1111/j.1440- 1797.2011.01512.x.

25. Friedman EA, Friedman AL, Eggers P. End stage renal disease in diabetic persons: Is the pandemic subsiding? Kidney Int Suppl.2006;70:S51-4.doi: 10.1038/sj.ki.5001978.

26. Martínez-Castelao A, Navarro-González JF, Górriz JL, de Alvaro F. The Concept and the epidemiology of diabetic nephropathy have changed in recent years. J Clin Med. 2015;4:1207-16. doi: 10.3390/jcm4061207.

Copyright (c) 2018 The Author(s); Published by Society of Diabetic Nephropathy Prevention. This is an open-access article distributed under the terms of the Creative Commons Attribution License (http://creativecommons.org/licenses/by/4.0), which permits unrestricted use, distribution, and reproduction in any medium, provided the original work is properly cited. 